\title{
Muslim Pilgrims' Use of Electronic Billboards (EBBs) and Message Recall: Examining the Effectiveness of the EBBs as a PSA Tool
}

\author{
Osman Gazzaz ${ }^{1}$, Fazal Khan ${ }^{1} \&$ Zafar Iqbal ${ }^{2}$ \\ ${ }^{1}$ Department of Communication Research and Media Affairs, the Custodian of Two Holy Mosques Institute for \\ Hajj and Omrah Research, Umm Al-Qura University, Makkah Al-Mukarramah, Saudi Arabia \\ ${ }^{2}$ Department of Mass Communication, School of Social Sciences and Humanities, National University of \\ Science and Technology (NUST), Islamabad, Pakistan \\ Correspondence: Zafar Iqbal, Department of Mass Communication, School of Social Sciences and Humanities, \\ National University of Science and Technology (NUST), Islamabad, Pakistan. Tel: 92-51-9085-3600. E-mail: \\ zafar.iqbal@s3h.nust.edu.pk.
}

Received: July 17, 2013 Accepted: January 1, 2014 Online Published: March 31, 2014

doi:10.5539/ass.v10n7p48 URL: http://dx.doi.org/10.5539/ass.v10n7p48

\begin{abstract}
The present study has examined the utility of the electronic billboards (EBBs) as a public service announcement (PSA) tool in the Holy Mosque area, Makkah Al-Mukarramah. Data were gathered from a non-probability sample of the Omrah pilgrims on the use, perceptions, and recall of the EBB messages. In-depth interviews with informants were also used to help interpret the data. Pilgrims' attention to the billboards and their recall of the messages were used as factors of billboard utility and effectiveness. On the basis of frequency distribution analysis coupled with simple elaboration through contingency and partial contingency tables, and zero-order and $5^{\text {th }}$ order partial correlations, the study concludes that despite their potential for high effectiveness the EBBs are not producing much of an impact on the pilgrims. Recommendations are proffered on how best to improve the EBBs utility as a PSA tool for the pilgrims.
\end{abstract}

Keywords: message recall, electronic billboards (EBB), public service announcement (PSA), survey

\section{Introduction}

\subsection{Significance \& Rationale of the Study}

Advertising through electronic billboards is part of the outdoor or the out of home advertising market and is one of the fastest growing segments of the media industry in the Western world (Lopez-Pumerarejo \& Bassell, 2009; Gambetti, 2010). Advances in technology has seen the electronic billboards (EBBs) become a useful tool of getting commercial and public service messages across to a target audience in areas that are crowded or highly frequented. Hence, in the West, the electronic billboards are now a common occurrence in market places, shopping malls, and on busy roads. This, in itself, is an ample testimony to their effectiveness as message carriers.

In view, perhaps, of their potential utility as a publicity and information dissemination tool, the Saudi authorities have set up digital billboards at prominent locations in close vicinity of the King Abdul Aziz \& the King Fahd Gates of the Masjid al-Haram Shareef. These billboards are mainly the scrolling boards that carry religious messages and public service announcements. (Note 1) Prima facie, the effectiveness assumption of the billboards may well be a safe assumption to make. Nevertheless, our contention is that putting up electronic billboards at some vantage points with electronic messages endlessly scrolling across the screens does not automatically guarantee the intended results. The literature on outdoor advertising and billboard signage tells us that location, size, message content, format and presentation variables are likely to compromise the presumed effectiveness of any information campaign through billboards (Osborne \& Coleman, 2008; Brown \& Rothschild, 1993; Calder \& Sternthal, 1980; Chevalier \& Mayzlin, 2006; Donthu, Cherian, \& Bhargava, 1993; Nelson, 2002; Raymond, 2003; Riebe \& Dawes, 2006).

The present study, therefore, examines the pilgrims' perceptions of and exposure to the messages scrolling across the electronic billboards, and their learning from those messages. Whether, at all, the pilgrims, notice these billboards and benefit from them. Hence, the broad research question being addressed here is: What is the 
effectiveness or utility of these scrolling billboards for the pilgrims? Effectiveness or utility of the electronic billboards implies the degree to which these billboards engage the pilgrims' exposure and attention. The construct effectiveness, in the minimum, also implies the extent to which the pilgrims learn and retain information from these boards. Learning, i.e., information recall, from the public information campaigns is likely to precede other persuasive effects of the campaigns such as attitudinal and behavioral effects.

\section{Literature Review}

\subsection{Factors in the Effectiveness of "EBBs" as a Publicity Tool}

Scant direct research on the factors that determine the effectiveness of the electronic billboards in information campaigns is available (Osborne \& Coleman, 2008). Much of the past research on the outdoor advertising campaigns predates the widespread use of technological advances in the outdoor advertising like the introduction of the digital billboards. Additionally, a persistent preoccupation of researchers with television advertising coupled with difficulty of employing experimental methods in outdoor advertising research leaves us with little available research wisdom on the utility of the EBBs as a publicity tool. Nevertheless, television advertising research and research on traditional billboards generally lead us to conclude that a number of factors like the structural characteristics of the billboards, the message characteristics, characteristics of audiences, their exposure patterns and the situational context of exposure, may influence audience learning and information retention, and in turn the billboards' effectiveness in information campaigns. Taylor, Franke, \& Bang (2006) has identified two criteria of billboard effectiveness as attention to billboards and improving recall. Hence use of clever creative execution of billboard messages is important. The traditional billboard literature has also identified short copy and simple message (single message, and use of clever phrases and/or illustrations) as one of the five principles of effective billboard advertising and higher recall (Taylor, Franke, \& Bang, 2006; Bhargava, Donthu, \& Carbon, 1994).

Additionally, for the digital billboards, distraction due to message clutter, the message scrolling speed, use of cellphones, and the presence of friends while frequenting the area have been found to significantly interfere with attention to billboards and thus recall of the billboard messages (Raymond, 2003; Riebe \& Dewes, 2006). Similarly, talking with others about the message content (Nelson, 2002), attitudes toward the utility of the billboards as information resource, and exposure and attention to the screens, and the structural features of the billboards like the size of the billboard, the wordiness or readability of the message, the use of animations \& action, the font size, the speed with which the messages scroll through the screen all may influence the billboard recall and their utility in information campaigns (Donthu, Cherian, \& Bhargava, 1993; Taylor, Franke, \& Bang, 2006; Osborne \& Coleman, 2008).

In view of the foregoing, and to adequately answer the above mentioned broad research question, the present study has posited the following specific research objectives for data generation:

\subsection{Objectives of the Study}

The main objectives of the study were:

1) To determine the pilgrims' use of and perceptions about the electronic scrolling billboards in the King Abdul Aziz \& the King Fahd Gates' area immediately outside the Masjid Al-Haram Shareef.

2) To determine the pilgrims recall of the billboard's messages.

3) To identify the factors that may help improve the utility of these billboards for the pilgrims.

\section{Methods}

\subsection{The Survey Instrument}

Given the present study's broad research question and the just mentioned specific objectives, triangulated procedures of data-collection were used. These comprised quantitative survey method and statistical description of data, and the interpretive analysis of a series of in-depth interview with educated informants. The survey instrument was developed in the months prior to Ramadan $1433(\mathrm{H})$ containing a mix of closed and open-ended questions tapping the pilgrims' use (extent of exposure \& attention) and perceptions of the EBBs, and their information recall, and their self-reported reasons for not recalling. The open-ended questions also allowed the audience to report in detail on their perceptions of how best to improve upon the utility of the present electronic billboards. Some of the closed-ended questions also tapped the pilgrims' demography and the context within which exposure to the billboards happened.

The structured questionnaire was developed in extensive discussion sessions with colleagues in the department well-experienced in data collection from the pilgrims in the field. The questionnaire was initially prepared in the 
English language that was subsequently got translated into the Urdu and the Arabic languages. These translated versions were closely scrutinized for their close conformity to the English version and the purpose of the study.

\subsection{Sample \& Data}

One hundred and ninety eight interviews (Note 2) were completed by four trained interviewers in three languages from a non-probability convenience sample of the male adult pilgrims frequenting the area immediately outside the King Abdul Aziz and the King Fahd gates of Al-Haram Shareef in the month of Ramadan $1433(\mathrm{H})$. The non-probability sampling had to be relied on because of the unavailability of the sampling frame chiefly due to the shifting nature of the population in the study area. The cases that never passed through the area were filtered out from the analysis. This left us with 175 usable cases. Of these little over 52\% of the respondents spoke Urdu and belonged to the Indo-Pak subcontinent, 5.2\% were Europeans who spoke the English language, and $42.5 \%$ were the Arabic speaking pilgrims.

Demographically, the sample had a median age of 42 years, a mean of 42.16 years, and a modal value of 30 years. In terms of the educational attainment of the sample, about half of the respondents had an educational attainment of higher secondary school or less. The bachelors' degree with $27.4 \%$ of the sample was the modal category. Little over $9 \%$ of the sample had no formal education and around $20 \%$ of the sample had completed masters or higher degrees. $77.7 \%$ of the sample comprised of the married individuals. Fifty nine percent of the cases were performing Omrah with family that year, and $39 \%$ were doing so in a group arrangement. The data was collected in different time periods of the day.

Two coders developed a detailed listing of the responses to each of the open-ended questions. The Inter-coder dispute on a few items was resolved through discussion and mutual consent and through the use of a catch-all miscellaneous category. The open-ended questions that entailed multiple responses were coded through multiple-response method while the rest were coded through multiple dichotomy method of coding. In addition, about eight hours of in-depth interviewing with five informed pilgrims was conducted by the first author that explored most of the above mentioned issues in greater details. (Note 3) These interviews were conducted separately with each one of the informants. These in-depth interviews yielded a wealth of evidence on how best to improve the utility and effectiveness of the EBBs as an information resource.

\section{Analysis \& Results}

The collected data were analysed through two types of analyses: the survey data through descriptive statistical analysis, and the interview data through interpretive analysis. Univariate and bivariate frequency distributions, and simple elaboration through contingency tables and Pearson product moment correlation coefficients were used for descriptive statistical analysis (de Vaus, 2002, p. 310). The following summary of the results has used figures from the valid percentages columns. (Note 4)

\subsection{The Pilgrims' Use of the Billboards}

A number of billboard-use variables were looked at. Operationally, the pilgrims' use of the billboards meant their exposure to the electronic billboards. The first billboard use item that was looked at determined whether, at all, the electronic billboards got noticed by the pilgrims. Seventy one percent of the pilgrims reported having seen the billboards. Of these, $77 \%$ had seen them in the study's area in question. When asked on a 3-point scale, ranging from 1 (never) to 3 (often), how often did they use the billboards when faced with a problem, $43.5 \%$ of the pilgrims reported getting help from the billboards, sometime or often, whereas $55.5 \%$ never used the billboards for help in problem situations. In terms of how important the billboards were as a source of information in difficulties, only $11 \%$ of the pilgrims ranked billboards in one of the top three sources of help in problem situations. The rest relied on other sources of information and help like family, friends, mualams, and the tour operators, or did not respond to the question.

As regards the frequency of exposure to the billboard messages, $29.9 \%$ of those who frequented the area did not look at the billboard, $49 \%$ looked at them sometime, and $21 \%$ looked at the messages often and very often. On the average, they spent 21 seconds seeing the message. The median time was 10 seconds and the modal value was five seconds.

\subsection{The Context of the Pilgrims' Exposure to the Electronic Billboards}

Table 1 shows the pilgrims' use of the billboards and the context of their exposure. Two exposure-related contextual variables in the study respectively were: the context within which the exposure happened, and the subsequent interpersonal interaction about the content of the message. These variables were included because, according to the available literature, these could potentially influence message recall or other effects of exposure. Over $30 \%$ of the respondents said they were usually alone in the area and $69.7 \%$ said they were usually in the 
company of friends and others when in the area. About $68 \%$ of the respondent never talked with others about the messages seen on the screen, the rest talked, at least, sometime about the billboard messages with others.

\subsection{The Pilgrims'Perceptions of the Electronic Billboards}

The pilgrims' perceptions about the electronic billboards were indexed essentially by three questions in the instrument: a closed-ended question, and a set of two open-ended questions. The close-ended question measured the degree of perceived usefulness or utility of the billboards to the respondents. On a 3-point scale, ranging from not at all helpful to very helpful, the respondents were asked about how much helpful did they think the billboard were to them. About $31 \%$ of the sample did not respond. The pilgrims' perceptions are shown in Table 2. Of those who responded, $30 \%$ perceived the billboards as not at all helpful to them. Close to $58 \%$ rated them as helpful, and another $12 \%$ perceived these as very helpful (Table 2 ).

The open-ended set tried to tap the pilgrims' perceptions about the structural characteristics of the billboards. The first question asked if they could indicate places where the EBBs were needed most. About fifty-four percent of the sample (94 of 175 cases) responded to the question by indicating at least one location. Of these little over 26\% ( 25 of 94 cases) indicated two locations, 10.3\% (10 of 94 cases) indicated three places. Out of 129 valid responses from 94 cases, three places stood out distinct from others in the responses; viz., the streets to Al-Haram (23.5\%), followed by the location of near the major gates of the Haram $(20.2 \%) \&$ the Haram rooftop $(16.3 \%)$.

The second open-ended question asked them to indicate changes to the present billboards in the area that would increase their utility to them as an information resource. Close to $62 \%$ (108 of 175) responded to this question proposing at least one change, and $38 \%$ of the cases (67 of 175) did not answer the question. A total of 143 responses were coded by two coders into seven broad categories with an inter-coder agreement of over 95 percent (disagreement in some five to six items were resolved through discussions). The categories for changes to the billboards that emerged from the coding of this open-ended query related to: (1) location, (2) number, and (3) size of the screens, format of the messages like (4) making the messages static or decreasing their scrolling speed, the nature of the content like (5) increasing the practical utility and relevance of the content, and (6) increasing the religious content of the messages, and (7) the additional use of other languages in the text.

Forty-nine percent of the 143 (cf. Table 2) responses related with structural changes to the billboards, categories listed at serial number 1 to 4 in the preceding paragraph. Of these, three structural elements stood out; viz, increasing the number of the screens (23\% of the responses), increasing the size of the screens $(20 \%$ of the responses), and changing the presentation format to static screens or to a slower scroll of the screen ( $4 \%$ of the responses, another $2 \%$ of the responses not shown in table had to do with changes in location). Little over $11 \%$ of the responses were about the changes to the nature of the information contents on the billboards, particularly increasing the practical relevance and informativeness of the content ( $8.4 \%$ of the responses), and increasing the religious content (about 3\%). Coding categories listed at serial number 5 and 6 in the above paragraph.

Casting the text of the message into other languages in addition to the Arabic and the English languages emerged as the single largest billboard change category comprising $37.8 \%$ of the pilgrims' responses.

\subsection{The Pilgrims' Recall of the Messages}

The unaided recall was examined and the pilgrims were asked in an open-ended query to recall whatever messages they had seen on the scrolling billboards. The answers were coded into a 3-point scale ranging from recalled no message to recalled part of a message to one complete message recalled. Table 3 reports univariate distribution of the pilgrims' score on the recall scales. Thirty-five percent of the sample ( 62 out of 175 cases) did not respond to the question. Of those (113 cases in all) who responded to the question, about $53.8 \%$ did not recall anything. Thirty-percent recalled part or some of the message and $6.2 \%$ recalled at least one complete message.

When asked about reasons for non-recall, 67 cases or 38.3\% of the sample gave 78 responses in all. About $72 \%$ of the responses cited inattention, $18 \%$ language, and another $9 \%$ wordy and fast moving text, and $1 \%$ of the reasons pertained to crowd congestion in the area.

\subsection{How the Recall Is Distributed in the Sample}

Recall was first examined in bivariate distribution across categories of exposure (cf. Table 4), then across categories of pilgrim groups (Table 4), and finally, by way of simple elaboration analysis, bivariate relationship between billboard exposure and recall was examined across categories of the variable "pilgrim groups" (Table 5). (Note 5) These tables suggest some interesting trends in the sample shedding some light on the utility and effectiveness of the billboards. Table 4 shows that there is no relationship between exposure and unaided recall. Although comparing $27.6 \%$ and $40.7 \%$ suggests trend in the right direction, the Goodman-Kruskal's tau of .01 
clearly shows that there is no relationship between the two variables. Does this mean that the billboards have no utility at all for the pilgrims in the sample? The answer lies in somewhat more perceptive analysis of the data here.

Table 5, for example, indicates a relationship between the two dichotomous variables of pilgrim groups and the message recall variable. (Note 6) Of the respondents who recalled some message, the proportion of the "Urdu speaking" group (around 25\%) was about half that of the mainly Arabic/English speaking "other pilgrims" (about 47\%) category. This means the variable "pilgrims group" is related to and has an effect on message recall in the sample. This is also in evidence from the Goodman-Kruskal's Tau of .22. Now this finding seems interesting in view of the fact that $62 \%$ of the "Urdu speaking" group versus $35 \%$ of the "other pilgrims" group perceives that the language of the billboards text need to be diversified to include other languages. The variable "pilgrim group" is, in fact, a surrogate for the language proficiency of the pilgrims. And the language proficiency is important if we consider the fact that the language of the billboards primarily was Arabic and secondarily English. This clearly implies that the variable "pilgrim group" might be a suppressor variable in the exposure-recall relationship suppressing it from showing up in the sample. This fact requires that the effect of the variable "pilgrim group" shall have to be partialled out or controlled for validly establishing the relationship in the sample.

Table 6 provides a first order partial for the effect of the billboard exposure on the pilgrims' recall with the pilgrim group being a control variable. Now we see a very clear effect of the billboard exposure on recall in the "other pilgrims" category. This also becomes evident if we compare the Goodman-Kruskal's Tau values of .03 for the Urdu-speaking group with that of .12 for the other pilgrims" category, a higher proportion of the "some exposure" group recalls message as compared to the "no exposure" group. Thus, the exposure is interacting with the "pilgrim group" variable; i.e., in fact, exposure is interacting with the language of the message to produce an effect on the message recall. This contingent role interpretation of the text's language becomes visible from the absence of any effect of the exposure on message recall in the "Urdu speaking" group of Table 6. This means that depending on the language of the text, the exposure does have an effect on message recall in the sample.

Table 1. Use of the billboards \& the context of exposure

\begin{tabular}{lcc}
\hline Pilgrims who ... & Percent & N \\
\hline Noticed the billboards & 70.5 & 173 \\
Saw the screen in the study area & 77.8 & 122 \\
Use the screens sometime/often in difficulty & 43.6 & 170 \\
Cited billboards as one of top three sources & 11.4 & 175 \\
Are usually alone while frequenting the area & 30.3 & 175 \\
Never talk about the EBBs messages with others & 67.5 & 154 \\
\hline
\end{tabular}

Table 2. Pilgrims' perceptions about the effectiveness of EBBs

\begin{tabular}{lcc}
\hline Frequency Distribution of the Pilgrims' Perceptions & Percent & N \\
\hline Perceived the screens as helpful & 70.3 & 121 \\
Proposed at least one new location & 54.0 & 175 \\
Streets to Al-Haram & 23.5 & 129 \\
Near the Haram Gates & 20.2 & 129 \\
On the rooftop of Al-Haram & 16.3 & 129 \\
At least one structural change to the EBBs & 62.0 & 175 \\
Changes in: location, size, number, format & 49.0 & 143 \\
Increase number of screens & 23.0 & 143 \\
Increase the size & 20.0 & 143 \\
Change the presentation format & 4.0 & 143 \\
Increase the practical relevance of the content & 8.4 & 143 \\
Increase the religious content & 3.0 & 143 \\
Include other languages & 37.8 & 143 \\
\hline
\end{tabular}


Table 3. Pilgrims' message recall

\begin{tabular}{lcc}
\hline Pilgrims who & Percent & N \\
\hline Recalled nothing from the screens & 63.7 & 113 \\
Recalled something from the screen & 30.1 & 113 \\
Recalled one complete sentence from the screen & 6.2 & 113 \\
\hline
\end{tabular}

Table 4. Message recall by exposure to the EBBs

\begin{tabular}{cccc}
\hline & & No Exposure \% & Some Exposure \% \\
\hline \multirow{2}{*}{ Recall } & No Recall & 72.4 & 59.3 \\
& Some Recall & 27.6 & 40.7 \\
& Total (N) & $100.0(29)$ & $100.0(81)$ \\
\hline
\end{tabular}

Goodman-Kruskal's tau $=.01$

Table 5 . Message recall by pilgrim groups

\begin{tabular}{cccc}
\hline & & Urdu-speaking \% & Other Pilgrims \% \\
\hline \multirow{2}{*}{ Recall } & No Recall & 75.5 & 53.3 \\
& Some Recall & 24.5 & 46.7 \\
& Total (N) & $100.0(53)$ & $100.0(60)$ \\
\hline
\end{tabular}

Goodman-Kruskal's tau $=.22$

Table 6 . Message recall by exposure by pilgrim groups

\begin{tabular}{lccccc}
\hline & \multicolumn{2}{c}{ Urdu-Speaking } & \multicolumn{2}{c}{ Other Pilgrims } \\
\cline { 3 - 6 } & & No Exp. \% & Some Exp. \% & No Exp. \% & Some Exp. \% \\
\hline \multirow{2}{*}{ Recall } & No Recall & 61.5 & 78.9 & 81.2 & 41.9 \\
& Some Recall & 38.5 & 21.1 & 18.8 & 58.1 \\
& Total (N) & $100.0(13)$ & $100.0(38)$ & $100.0(16)$ & $100.0(43)$ \\
\hline \multicolumn{2}{l}{ Goodman -Kruskal's Tau: } & \multicolumn{2}{c}{$(03)$} & \multicolumn{2}{c}{$(.12)$}
\end{tabular}

The issue that now becomes important is to determine whether this relationship between exposure and recall that we found in the sample is spurious. Hence, we built into our design four other variables; viz, age, education, perceived helpfulness of the billboards, and talking/interaction with others about the billboard messages. Table 1 below provides zero-order and $5^{\text {th }}$ order partial correlation coefficients among the six predictors and the criterion variable of message recall. The Pearson product moment correlation coefficient among these variables varied between the weak to moderate range ( $r$ of -.16 to .27 ). The fifth order partial coefficient $(r=.19)$ signifies that even if the effect of age, education, perceived helpfulness, pilgrim group, and talking about the message with others is removed, there does remain some relationship of exposure with recall. 
Table 7. Zero-order correlations between the predictor $\&$ criterion variables*

\begin{tabular}{|c|c|c|c|c|c|c|c|c|}
\hline & $\begin{array}{c}\text { Variables } \\
\nabla\end{array}$ & 1 & 2 & 3 & 4 & 5 & 6 & 7 \\
\hline 1. & Exp. & 1 & & & & & & \\
\hline 2. & Recall & $.26(108)^{* *}$ & 1 & & & & & \\
\hline 3. & Age & $-.13(145)$ & $-.16(111)$ & 1 & & & & \\
\hline 4. & Educ. & -.05 (139) & $.18(107)$ & $-.32(167)$ & 1 & & & \\
\hline 5. & Pilgrim Group & $.02(145)$ & $.18(111)$ & $.01(173)$ & $-.04(167)$ & 1 & & \\
\hline 6. & Interaction & $.32(144)$ & $.27(109)$ & $-.04(152)$ & $.18(146)$ & $-.08(152)$ & 1 & \\
\hline 7. & Usefulness & $-.00(116)$ & $.22(95)$ & $.04(119)$ & $.10(116)$ & $.13(119)$ & $.15(116)$ & 1 \\
\hline & Mean & 1.99 & 1.79 & 42.61 & 3.27 & 1.48 & 1.38 & 1.83 \\
\hline & $\mathrm{Sd}$ & .86 & 1.07 & 14.65 & 1.28 & .50 & .62 & .63 \\
\hline
\end{tabular}

${ }^{*}$ The $5^{\text {th }}$ order partial correlation between Exp. and Recall was (.19) after the effects of Age, Educ., Pilgrim Group, Interaction, and Usefulness were partialled out.

${ }^{* *}$ Figures in parenthesis are pairwise Ns.

\subsection{The In-Depth Interviews with the Informants: An Interpretive Summary}

The four informants chosen for the interviews were post-graduate students, who had considerable experience of surveying the pilgrims. These respondents were asked to see the scrolling billboards for ten to fifteen minutes with a view to assessing their utility for the pilgrims. Each one was interviewed in isolation from others about the structural characteristics of the billboards; location, message format, and contents. All four virtually pointed out and identified identical deficiencies in the screens that if addressed would make the EBBs very effective resource tool for the pilgrims. Their responses, though more detailed coincided in broad with the kind of factors that emerged in the survey data. For example, much like the survey data, the informants stressed the need for increasing the number of screens, the size of the screens, and decreasing the scrolling speed of the messages. The informants said that the messages were wordy, fast moving, and not readable. The text needed to be very short and if possible accompanied with illustrations. Messages needed to be cast in other languages (like the Urdu, the Bengali, the Malay, the Persian, and the French languages) in equal proportions beside the Arabic and the English languages. The content of the message needed to be focused on practical problems of the pilgrims like: including direction pointers, emergency numbers, crowd situations, complaint offices, where to find wheelchairs, and other needed resources, where to find and go to if a pilgrim gets lost, how to find medical help, or approach a muttawiff, and even the practical religious content highlighting practical matters pertaining to ritual aspects of Islam. In terms of the message formatting \& presentation, the informants stressed the need for using catchy slogans or bulleted points and greater reliance on illustrations. Long and wordy messages were not fully remember-able or recallable. In terms of locations, the informants identified such areas that were without screens but could count as very strategic points. For example, areas like: the Haram rooftop, near the Haram gates, and on the streets in the Haram vicinity (on the Ajyad Street, the Ibrahim Khaleel Street, the Jurval Street, the area around the King Abdullah Extension Project, and in the Jabal Omar side, the areas immediately outside the Safa and the Marwa ends of the Haram Shareef).

\section{Conclusion \& Recommendations}

Broadly speaking the study examined two interrelated factors of the EBBs effectiveness: their capacity to engage the pilgrims' attention, and their capacity to produce awareness and learning. The main conclusion derivable from the above analysis of the data is that despite their potential for great utility and effectiveness for the pilgrims the EBBs were not that much effective in terms of the just mentioned two factors of effectiveness. Potential for effectiveness is instanced by the evidence of the effect of exposure on recall in the Arabic/English speaking "other pilgrims" category (cf. Table 6), and by weak but persistent correlation instanced by the 5th order partial coefficient of .19. And also the evidence that about $70 \%$ of the pilgrims perceived the billboards as helpful point to their potential for effectiveness. Limited effectiveness, on the other hand, is established in the data not only by the facts that $50 \%$ of the sample does not show any effect at all and that only $6 \%$ of the sample is able to recall one complete sentence but also by such other empirical facts that indicate the failure of the 
billboards to engage the attention of the pilgrims. For example, $30 \%$ of the sample does not look at the EBBs and does not get engaged and mere $21 \%$ of the sample looks at the screen often or very often, $68 \%$ of the sample does not talk about the message with others with only $5 \%$ of the sample talking about the messages often or very often with others.

Based on the study's data and the just mentioned conclusion, the following recommendations, pertaining to the structural and substantive characteristics of the EBBs, are proffered to increase their utility as a public service announcements (PSA) tool:

1) That bigger, and non-scrolling, digital screens should be installed in new locations around the built-up areas of the Haram Shareef, on its rooftops, and on the proximal ends of the streets to Al-Haram.

2) That the message should be simple preferably limited to one short sentence.

3) That where possible illustrations should also be used.

4) That the text should be cast in bigger type-size.

5) That the screen should change after every 10 to 12 seconds.

6) That the text should be cast in the Urdu, the Persian, the Malay, the Bengali, and the French languages besides the present Arabic and the English languages.

7) That where non-Arabic language is employed for the verses from the Holy Quran or the traditions of the Prophet (May the eternal peace and blessings of Allah be upon him) due care should be observed in the translations.

8) That the message content should have practical relevance for the pilgrims helping them deal with day to day problems with ease and facility; e.g., where to find the wheelchairs, direction of toilets, emergency numbers, guidance to health clinics, complaint offices, bus stops etc. or finding out lost family members and friends, and guidance on how best to perform Hajj and Omrah rituals.

\section{References}

Bhargava, M., Donthu, N., \& Carbon, R. (1994, March/April). Improving the Effectiveness of outdoor advertising: Lessons from a study of 282 campaigns. Journal of Advertising Research, 46-55.

Brown, T., \& Rothschild, M. (1993, June). Reassessing the Impact of Television Advertising Clutter. Journal of Consumer Research, 20, 138-146. http://dx.doi.org/10.1086/209339

Calder, B., \& Sternthal, B. (1980, May). Television Commercial Wearout: An Information Processing View. Journal of Marketing Research, 17, 173-186. http://dx.doi.org/10.2307/3150928

Chevalier, J., \& Mayzlin, D. (2006, August). The Effects of Word of Mouth on Sales: Online Book Reviews. Journal of Marketing Research, 43, 345-354. http://dx.doi.org/10.1509/jmkr.43.3.345

de Vaus, D. A. (2002). Surveys in Social Research (5th ed.). London: Routledge.

Donthu, N., Cherian, J., \& Bhargava, M. (1993, May). Factors Influencing Recall of Outdoor Advertizing. Journal of Advertizing Research, 33, 64-72.

Gambetti, R. (2010). Ambient Communication: How to Engage Consuers in Urban Touch-Ponts. California Management Review, 53(3), 34-51. http://dx.doi.org/10.1525/cmr.2010.52.3.34

Lopez-Pumerarejo, T., \& Bassell, M. (2009, Fall). The Renaissance of Outdoor Advertising: From Harlem to Hong Kong. American Journal of Business, 24(3), 33-39. http://dx.doi.org/10.1108/19355181200900009

Nelson, M. (2002, March). Recall of Brand Placements in Computer/Video Games. Journal of Advertizing Research, 42, 80-92.

Osborne, A. C., \& Coleman, R. (2008, Spring). Outdoor Advertising Recall: A Comparison of Newer Technology and Traditional Billboards. Journal of Current Issues and Research in Advertizing, 30(1), 13-30. http://dx.doi.org/10.1080/10641734.2008.10505235

Raymond, J. (2003). When the Mind Blinks: Attentional Limitations to the Perception of Sequential Visual Images. In L. M. Scott, \& R. Batra (Eds.), Persuasive Imagery: A Consumer Response Perspective (pp. 59-74). Mahwah, NJ: Lawrence Erlbaum Associates.

Riebe, E., \& Dawes, J. (2006, January). Recall of Radio Advertizing in High and Low Clutter Formts. International Journal of Advertizing, 25, 70-86. 
Taylor, C. R., Franke, G. R., \& Bang, H.-K. (2006, Winter). Use and effectiveness of billboards. Journal of Advertising, 35(4), 21-34. http://dx.doi.org/10.2753/JOA0091-3367350402

\section{Notes}

Note 1. Of late two big sized, static-screens, digital billboards have been mounted on the wall of Safwa towers facing the KAA Gate of the Haram Shareef. Messages on these billboards rotate every 5-8 seconds. These billboards were not around at the time of data collection for the present study in Ramadan 1433.

Note 2. Out of an intended 200 completed questionnaires, two were discarded: one was found to be incomplete and the second included a non-adult as a respondent.

Note 3. The interviews were audio-taped for interpretive analysis.

Note 4. The missing data is excluded from percentage calculations.

Note 5. The ordinal variables of frequency of exposure and extent of recall were each recoded into dichotomous variables respectively comprising no exposure and some exposure, and no recall and some recall categories.

Note 6. The pilgrims were divided into two groups on the basis of the country of origin. The pilgrims from India and Pakistan comprised the Urdu speaking group, and the pilgrims from the Arabic speaking countries and the English speaking European pilgrims were put together in the other pilgrims' category. This division was necessitated because the billboard messages comprised these two languages only. Urdu did not form the text of the study's billboards.

\section{Copyrights}

Copyright for this article is retained by the author(s), with first publication rights granted to the journal.

This is an open-access article distributed under the terms and conditions of the Creative Commons Attribution license (http://creativecommons.org/licenses/by/3.0/). 